\title{
Influence of Unloading Conditions of Confining Pressure on the Compressive Strength and Permeability of Deep Mudstone
}

\author{
Tianyu Xin (D), ${ }^{1}$ Yashengnan Sun $\left(\mathbb{D},{ }^{2}\right.$ Junguang Wang $\mathbb{D}^{1},{ }^{1}$ and Weiji Sun ${ }^{1}$ \\ ${ }^{1}$ Institute of Mechanics \& Engineering, Liaoning Technical University, Fuxin 123000, China \\ ${ }^{2}$ College of Safety Science and Engineering, Liaoning Technical University, Fuxin 123000, China \\ Correspondence should be addressed to Junguang Wang; 307446930@qq.com
}

Received 15 November 2020; Revised 30 December 2020; Accepted 25 January 2021; Published 9 March 2021

Academic Editor: Lei Wang

Copyright (c) 2021 Tianyu Xin et al. This is an open access article distributed under the Creative Commons Attribution License, which permits unrestricted use, distribution, and reproduction in any medium, provided the original work is properly cited.

To investigate the compressive strength and permeability of deep mudstone under stress disturbance, a triaxial rheometer is used to conduct seepage experiments on mudstone specimens with different buried depths under triaxial compression and unloading conditions. The experimental results show that the compressive strength of mudstone specimen with a depth of $1000 \mathrm{~m}$ is much lower than that of specimen with a depth of $200 \mathrm{~m}$, and the compressive strength of mudstone increases with the increase in confining pressure. Under constant axial pressure and unloading of the confining pressure, the mudstone with a depth of $200 \mathrm{~m}$ exhibits brittle failure, and the strain fluctuates in a pointwise manner with the increase in axial stress. In this case, the mudstone with a depth of $1000 \mathrm{~m}$ exhibits a transition from brittle failure to ductile failure, and the strain fluctuates linearly with the axial stress. Further, when the volumetric strain change reaches 0.01 , it shows an oblique " $Z$ " fluctuation. During the initial stage of unloading of confining pressure, the permeabilities of both the mudstone specimens (with depths of 200 and $1000 \mathrm{~m}$ ) decrease gradually. As the confining pressure is unloaded, the permeability of mudstone with a depth of $1000 \mathrm{~m}$ increases. Until the specimen is completely destroyed, the permeability of mudstone increases rapidly. Overall, this study can serve as a useful reference for analyzing the engineering disasters associated with deep rock mass, tunnel ventilation, and gas storage.

\section{Introduction}

During the process of underground mining, roadway excavation and heading face cause the surrounding rock to produce stress disturbance and break the equilibrium state of coal and rock, which is usually manifested as axial loading and confining pressure unloading. This phenomenon is more obvious during the deep mining of coal and rock.

Traditionally, the mechanical properties of coal and rock are primarily investigated using experimental triaxial compression test [1-3]. However, the damage characteristics of rock masses after direct loading and after loadingunloading cycle are quite different. Several researchers have intensively studied the unloading characteristics of rock. Qiu et al. [4] used a new loading path and operation method to conduct confining pressure unloading tests under different unloading rates for clearly understanding the effect of unloading rate on the mechanical properties of rock. It was found that the unloading rate of the confining pressure had a significant impact on the deformation of marble, and the initial confining pressure level mainly controlled the corresponding influence law. Liang et al. [5] continuously loaded argillaceous limestone specimens to the residual stage under different initial confining pressures in the conventional triaxial compression test. The influence of confining pressure and loading-unloading cycles on the mechanical properties of residual rocks was examined through the stress and strain characteristics and acoustic emission monitoring. In addition, the yielding prediction information about the rock in the loading stage of confining pressure was analyzed. Huang et al. [6] used unloading tests to examine the deformation and fracture characteristics of rocks under unloading. Chen et al. [7] investigated the influence of unloading process on the permeability and damage deformation of coal by X-ray computed tomography (CT). Kang et al. [8] performed X-ray diffraction (XRD) measurements, 
longitudinal wave velocity measurements, uniaxial compression tests, and dynamic impact tests on granite from Daliuhang Gold Mine, Yantai, Shandong, China, at various burial depths to reveal the static and dynamic mechanical properties of the rock specimens. Based on the energy theory, Zhao et al. [9] examined the strain energy conversion process of rocks with initial confining pressures of 10, 20, and $30 \mathrm{MPa}$ under different unloading paths.

The differences in mechanical properties can lead to variation in permeability characteristics. To this end, the permeability characteristics of coal rock under unloading conditions have been widely investigated in the recent years. Yin et al. [10], Zhang et al. [11], and Xue et al. [12] studied the impact of unloading rate of confining pressure on the damage and seepage characteristics of gas-bearing coals and suggested that the increase in unloading rate causes a decrease in the peak strength and an increase in the permeability. Ren et al. [13] studied the dynamic behavior and permeability characteristics of coal rocks under strong disturbance and indicated that the permeability of sample with largest disturbance stress before failure was generally higher than those of the other samples. Besides, several other researchers (Pan and Connell [14], Wang and Du [15], Xie et al. [16], and Zhang et al. [17]) systematically explored the mechanical or permeability properties of coals under confining pressure unloading through triaxial compression tests.

Although the existing studies provided useful insights into the mechanical and permeability characteristics of coal and rock under unloading and simulated the stress environment of deep coal and rock, the difference between deep and shallow rocks has been mostly ignored $[18,19]$. In this study, based on the difference between deep and shallow rocks, the compressive strength and permeability characteristics of deep mudstone under confining pressure unloading are investigated through comparative experiments. The results can serve as an effective guide for the analysis of engineering disasters associated with deep rock mass, roadway ventilation, and gas storage.

\section{Experimental Device and Scheme}

2.1. Experimental Device. The experimental device is a triaxial rheometer developed by Wuhan University of Science and Technology, China, as shown in Figure 1. The device includes a numerically controlled pressure system, osmotic system, triaxial pressure chamber, data acquisition system, and auxiliary system. It can be used to realize multifield coupling of stress field, seepage field, gas pressure field, and so forth. The maximum confining pressure, maximum axial load, and accuracy of the device are $50 \mathrm{MPa}, 650 \mathrm{kN}$, and $\pm 0.2 \mathrm{MPa}$, respectively. A high-precision axial linear variable differential transformer (LVDT) and special circumferential strain sensor are used to measure the axial strain and circumferential strain simultaneously.

2.2. Experimental Method. The mudstone used in the test was taken from the 12th mining area of Pingmei coal field. Due to the special geological structure of Pingmei mining area, the same geological layer shows different buried depth in different working faces. Two mudstone specimens with different buried depths of $200 \mathrm{~m}$ and $1000 \mathrm{~m}$ were taken from working faces 17120 and 31030 of the 12th mining area of Pingmei coal field, respectively. The specific sampling locations are shown in Figure 2. According to the requirements of the national standard, the diameter $(\varphi)$ and height (h) of a standard cylindrical specimen are $50 \mathrm{~mm}$ and $100 \mathrm{~mm}$, respectively. The cut specimen is shown in Figure 3(a).

(1) Triaxial compression test: Three values of confining pressure are considered: 0,15 , and $30 \mathrm{MPa}$. First, $\sigma_{1}=\sigma_{2}=\sigma_{3}$ are loaded to a hydrostatic pressure of $30 \mathrm{MPa}$ at a rate of $0.01 \mathrm{~mm} / \mathrm{s}$. Keeping $\sigma_{2}=\sigma_{3}$ constant at $30 \mathrm{MPa}$, loading of $\sigma_{1}$ is continued at a rate of $0.02 \mathrm{~mm} / \mathrm{s}$ until the specimen is destroyed.

(2) Seepage with confining pressure unloading: First, $\sigma_{1}=\sigma_{2}=\sigma_{3}$ are loaded to hydrostatic pressure of $30 \mathrm{MPa}$ at a loading rate of $0.01 \mathrm{~mm} / \mathrm{s} . \sigma_{2}=\sigma_{3}$ are kept constant at $30 \mathrm{MPa}$, and $\sigma_{1}$ is further loaded to $80 \mathrm{MPa}$ at a rate of $0.02 \mathrm{~mm} / \mathrm{s}$. Keeping $\sigma_{1}$ unchanged, $\sigma_{2}=\sigma_{3}$ are unloaded at a rate of $0.02 \mathrm{~mm} / \mathrm{s}$, $3 \mathrm{MPa}$ per discharge. The variation in permeability of each mudstone specimen at each unloading ( $30 \mathrm{~min})$ is measured until the specimen is completely destroyed. The specimen is replaced, and all the steps are repeated until the end of the test. The stress path during the confining pressure unloading test is shown in Figure 3(b).

2.3. Principle and Method of Gas Permeability Test. In the quasistatic method, the inlet end of the pressure chamber is used to control the gas pressure on the lower surface of the specimen. This method is used for examining the gas permeability. The outlet end of the pressure chamber (the upper surface of the specimen) is connected to the atmosphere [20]. After the pressure difference between the upper and lower end surfaces allows steady-state seepage through the specimen, the change in gas pressure at the inlet end is recorded as a function of time to determine the gas permeability of the specimen. A schematic of test is shown in Figure 4 .

The general form of the partial differential equation for gas percolation is

$$
\nabla \cdot\left(\delta \frac{K}{\mu} \frac{p}{Z} \nabla p\right)=\frac{\partial(\phi p / Z)}{\partial t},
$$

where $\delta$ is the inertial-turbulence correction coefficient; $K$ is the gas permeability $\left(\mathrm{m}^{2}\right) ; \mu$ is the viscosity of the gas $(\mathrm{Pa} \cdot \mathrm{s}) ; p$ is the gas pressure $(\mathrm{MPa}) ; \phi$ is the porosity; $Z$ is the deviation factor, the modifier of the ideal gas equation of state; $T$ is the seepage time $(s)$.

In the quasistatic method, it is assumed that the gas seepage satisfies the following conditions: (1) Darcy's law is established, $\delta=1$; (2) the seepage gas is an ideal gas, $Z=1$.

Therefore, the one-dimensional gas percolation equation is simplified as follows: 

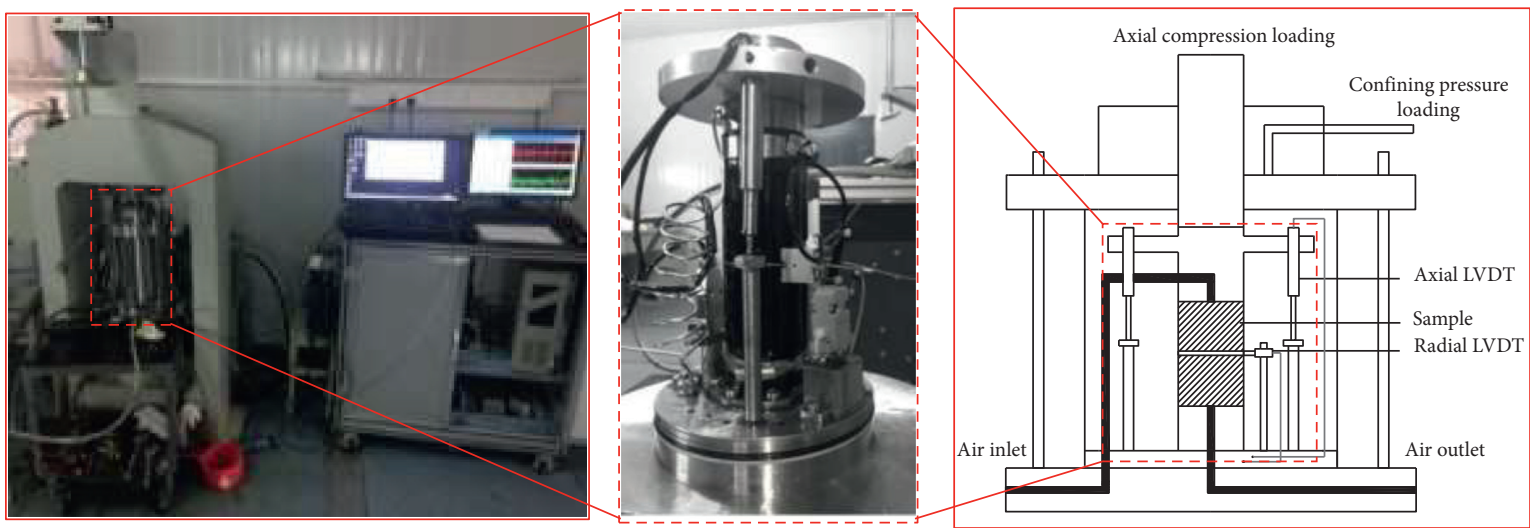

FIgURE 1: Schematic and actual image of triaxial rheometer.
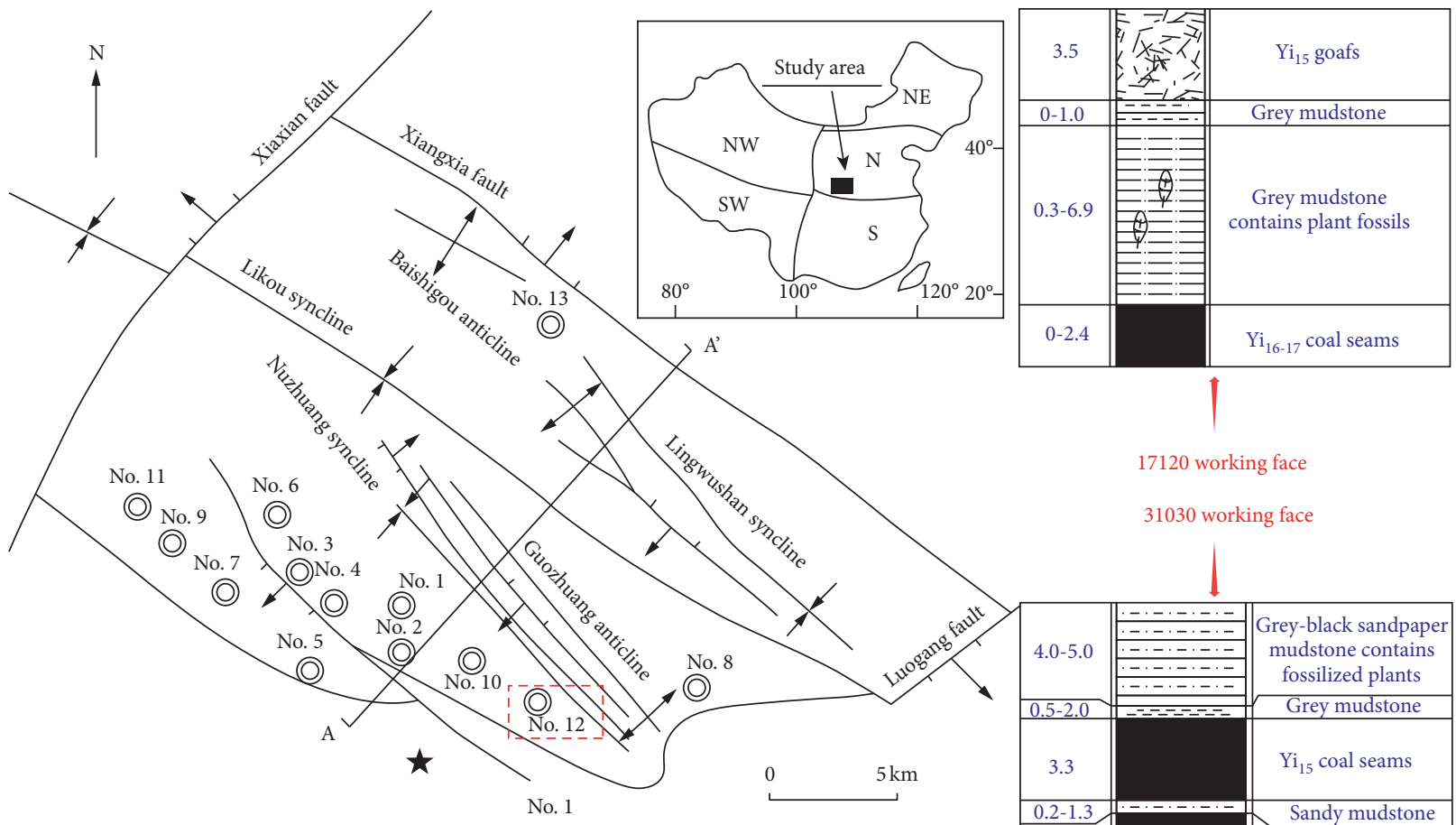

17120 working face 31030 working face
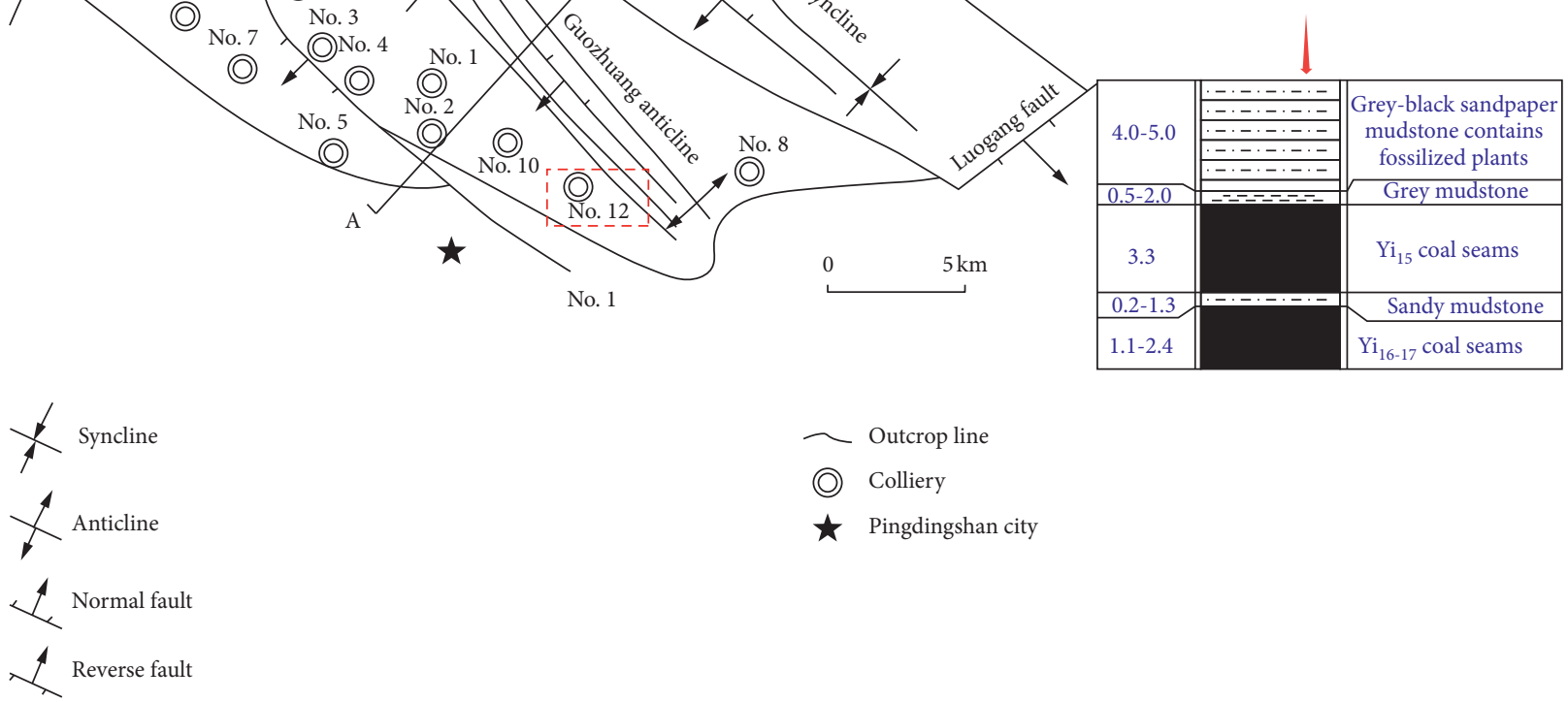

$\sim$ Outcrop line

(O) Colliery

$\star$ Pingdingshan city

FIgURE 2: Sampling locations.

$$
\frac{K}{2 \mu} \frac{\partial^{2} P^{2}}{\partial x^{2}}=\phi \frac{\partial P}{\partial t}
$$

During the test, the following initial condition is satisfied: when $t=0,\left.P\right|_{x=0}=P_{1}$. Further, the boundary condition is that when $t \geq 0, P_{\mid x=L}=P_{0}$. Since the permeability of the rock $<10-17 \mathrm{~m}^{2}$ [21], it can be assumed that $\phi \approx 0$. Thus, equation (2) can be solved, and the gas pressure in the pressure chamber can be obtained as follows:

$$
P(x)=\sqrt{P_{1}^{2}\left(1-\frac{x}{L}\right)+P_{0}^{2}\left(\frac{x}{L}\right)}(0 \leq x \leq L),
$$




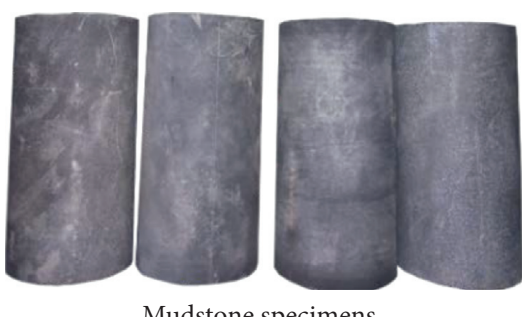

Mudstone specimens

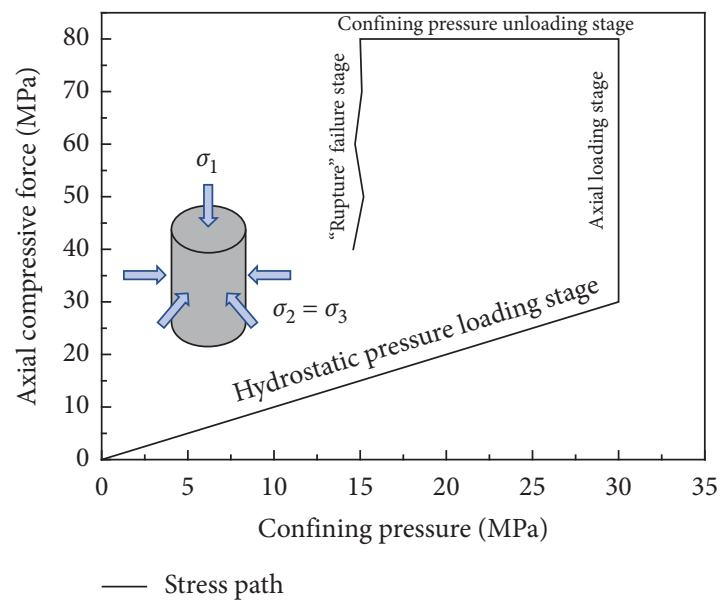

(b)

FIGURE 3: Mudstone specimens and stress path during the confining pressure unloading test.

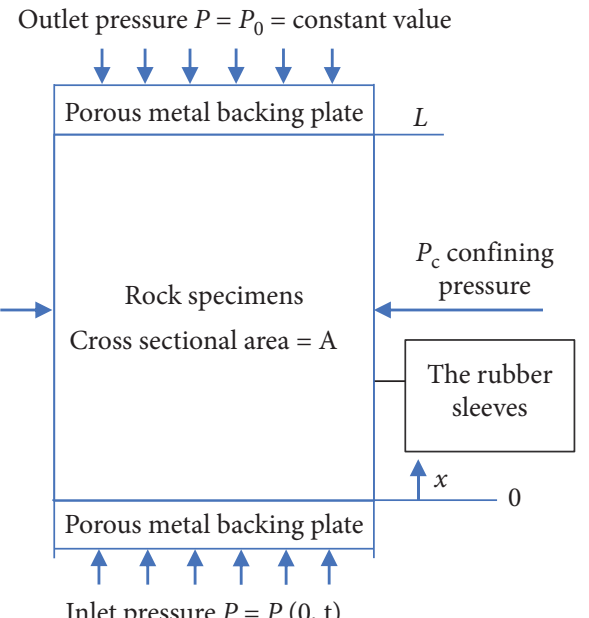

Inlet pressure $P=P(0, \mathrm{t})$

(a)

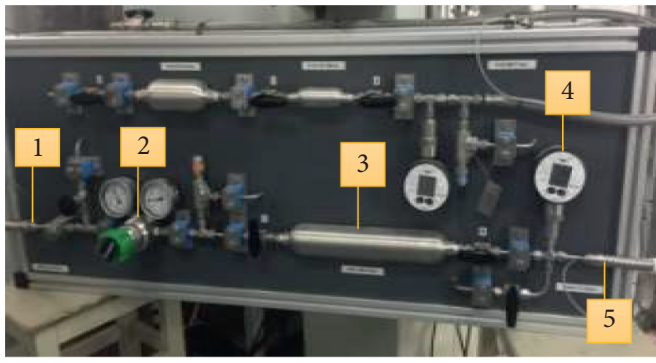

1. Gas injection port;

2. Dropping valve;

3. Volumetric flask;

4. High precision air pressure sensor;

5. The gas inlet end.

Figure 4: Principle of quasistatic method and the corresponding experimental system. (a) Principle of quasistatic method; (b) apparatus for measuring the permeability by transient method.

where $P_{1}$ is the inlet pressure of the pressure chamber $(\mathrm{MPa})$; $P_{0}$ is atmospheric pressure $(0.1 \mathrm{MPa}) ; x$ is the distance between the cross section at any point inside the test piece and the test-piece cross section at the inlet $(\mathrm{m}) ; L$ is the length of the test piece $(m)$.

The gas seepage in the test satisfies Darcy's law, so

$$
Q=-\frac{k A}{\mu} \frac{\partial P}{\partial x} .
$$

Substituting equation (3) into (4) and setting $x=L$, the expression of the gas flow rate at the outlet end of the pressure chamber can be obtained as

$$
Q_{1}=\frac{k A\left(P_{0}^{2}-P_{1}^{2}\right)}{2 \mu L P_{1}} .
$$

It is assumed that, at $t=0$ and $t=\Delta t$, the pressure at the intake end is $P_{1}$ and $P_{1}-\Delta P_{1}$, respectively. Therefore, average pressure $P_{\text {moy }}=P_{1}-\Delta P_{1} / 2$, where $\Delta P_{1}$ is the pressure change at the intake end.

Within $\Delta t$, the gas quality in the pressure chamber changes as $\Delta m=\nu \times \Delta \rho_{1}$. According to assumption (2), from the ideal gas state equation $p / \rho=c$, we get

$$
\begin{aligned}
\Delta m & =v \times \frac{\rho_{1} \times \Delta P_{1}}{P_{1}}, \\
\Delta m & =\rho_{\text {moy }} \times Q_{\text {moy }} \times \Delta t, \\
Q_{\text {moy }} & =\frac{v \Delta P_{1}}{P_{\text {moy }} \Delta t} .
\end{aligned}
$$


According to equations (5) and (8), the gas permeability of rock sample can be expressed as follows:

$$
k=\frac{2 \mu L \Delta P_{1}}{S\left(P_{\text {moy }}^{2}-P_{0}^{2}\right) \Delta t},
$$

where $Q$ is the gas flow rate $\left(\mathrm{m}^{3} / \mathrm{s}\right) ; S$ is the cross-sectional area of the rock sample $\left(\mathrm{m}^{2}\right) ; v$ is the volume of rock sample; $\rho_{\text {moy }}$ and $Q_{\text {moy }}$ are the indoor average gas density $\left(\mathrm{kg} / \mathrm{m}^{3}\right)$ and average gas flow rate at the chamber inlet end $\left(\mathrm{m}^{3} / \mathrm{s}\right)$ in the interval $\Delta t$, respectively.

\section{Results and Discussion}

3.1. Effect of Confining Pressure on the Stress-Strain Curve and Compressive Strength of Deep Mudstone. Through triaxial compression test, compressive strength of mudstone specimens with different buried depths is obtained, as shown in Table 1, and the stress-strain curves of some mudstone specimens are shown in Figure 5. It is clear that the compressive strength of mudstone with a depth of $1000 \mathrm{~m}$ is much smaller than that of mudstone with a depth of $200 \mathrm{~m}$. This is because the mudstone with buried depth of $1000 \mathrm{~m}$ remains in a high stress state for a long time. During mining, the stress on the mudstone is released in a short time, which causes the internal structure to exhibit plastic deformation, and the compressive strength is reduced. The mudstone buried at a depth of $200 \mathrm{~m}$ contains a small amount of white $\mathrm{SiO}_{2}$ mineral particles, which enhances the compressive strength [22]. The composition of mudstone is quantitatively analyzed based on fluorescence spectroscopy, and the results are shown in Table 2. Compared to the conventional hard rock [19], the specimen also experiences sudden release of ground stress, leading to the initial damage of internal structure, but it shows completely opposite results. It is considered that the initial damage of mudstone will not have a decisive influence on its strength. Here, the mudstone with a burial depth of $200 \mathrm{~m}$ has a higher $\mathrm{SiO}_{2}$ content, which mainly results in its higher strength.

Figure 6 shows the relationship between peak strength of mudstone and confining pressure. The peak strength of the two types of buried mudstone increases linearly with the increase in the confining pressure. It can be seen from the slope of the fitting curve in Table 3 that the variation rates of the peak strength of the two buried mudstone specimens are slightly different. When the confining pressure rises from $0 \mathrm{MPa}$ to $30 \mathrm{MPa}$, the average peak strength of mudstone buried at a depth of $200 \mathrm{~m}$ increases by $78.95 \mathrm{MPa}$ (from $70.21 \mathrm{MPa}$ to $149.16 \mathrm{MPa}$ ), while that of mudstone buried at a depth of $1000 \mathrm{~m}$ increases by $73.7 \mathrm{MPa}$ (from $42.29 \mathrm{MPa}$ to $115.99 \mathrm{MPa})$. It is clear that the variation rate of peak strength for mudstone buried at a depth of $200 \mathrm{~m}$ is higher. On the other hand, from the perspective of strain (left side of the axis in Figure 5), when the confining pressure increases, the initial strain of mudstone with a buried depth of $200 \mathrm{~m}$ is smaller than that of mudstone with a buried depth of $1000 \mathrm{~m}$. This implies that, compared to the mudstone specimen with buried depth of $1000 \mathrm{~m}$, the effect of confining press on the deformation is stronger for the mudstone specimen with buried depth of $200 \mathrm{~m}$.

\subsection{Influence of Confining Pressure Unloading on the Volume} Strain of Deep Mudstone. Due to the anisotropy between mudstone specimens, it is crucial to select the maximum value of axial pressure during the confining pressure unloading test. After several experiments, two representative deep mudstone specimens were selected for the analysis.

The relationship between strain of mudstone specimen and axial stress (confining pressure) is shown in Figure 7 (Figure 8). The three important stages of the test process can be clearly identified from the diagram, namely, axial compression loading stage, confining pressure unloading stage, and "fracture" stage. The variation trend of strain in the axial compression loading stage is basically the same for the two specimens; the loading strain gradually increases with the increase in axial pressure. Unlike triaxial compression tests, the two deep buried mudstones exhibit significantly different response in the confining pressure unloading stage. The volume strain of mudstone with buried depth of $200 \mathrm{~m}$ is negligibly changed during this stage, and the axial stress remains basically constant at its maximum value and fluctuates in a pointwise manner until the confining pressure is unloaded to $6 \mathrm{MPa}$, which indicates fracture of the specimen, where the volume strain drops rapidly, and the mudstone exhibits extremely strong brittle characteristics. The volume strain $(\Delta \varepsilon)$ of the mudstone specimen with buried depth of $1000 \mathrm{~m}$ is close to 0.02 at this stage. During the initial stage, the axial stress linearly fluctuates with the increase in strain. When the value of $\Delta \varepsilon$ approaches 0.01 , axial stress fluctuates with strain in an oblique "Z" fashion. Further, it shows a gradual decline and is unable to return to the initial level. This indicates that the unloading of confining pressure causes circumferential expansion and axial compression. Therefore, the axial compression causes a small decrease of 63.12 MPa in stress when the confining pressure is unloaded to $12 \mathrm{MPa}$, which indicates destructive strength, where the volume strain drops rapidly. In the confining pressure unloading phase, the failure form of deep mudstone changes from brittle fracture of shallow mudstone to fracture growth controlled by lateral stress, that is, from shallow dynamic failure to deep quasistatic failure. The mechanical response is changed, and the fragility of the shallow part is transformed into potential ductile failure of the deep part.

\subsection{Permeability Characteristics of Deep Mudstone. The} permeability of mudstone is closely related to its porosity and structural characteristics. The better the pore connection, the higher the permeability. By comparison, the pore characteristics of the two deep buried mudstones are similar. Further, the permeabilities of the two mudstones are nearly similar before confining pressure unloading, but they become different during the unloading process. This indicates that the structural characteristics of the two deep buried mudstones vary differently during the unloading process.

The relationship between mudstone permeability and confining pressure is shown in Figure 9. In conventional 
TABLE 1: Compressive strength of different specimens.

\begin{tabular}{lcccc}
\hline Specimen number & Buried depth $(\mathrm{m})$ & Confining pressure $(\mathrm{MPa})$ & Diameter $(\mathrm{mm})$ & Compressive strength $(\mathrm{MPa})$ \\
\hline MS-2-0-1 & 200 & 0 & 49.97 & 70.85 \\
MS-2-0-2 & 200 & 0 & 50.21 & 71.20 \\
MS-2-0-3 & 200 & 0 & 48.97 & 68.58 \\
MS-2-15-1 & 200 & 15 & 49.91 & 121.50 \\
MS-2-15-2 & 200 & 15 & 51.24 & 123.52 \\
MS-2-15-3 & 200 & 15 & 50.37 & 117.26 \\
MS-2-30-1 & 200 & 30 & 50.01 & 148.00 \\
MS-2-30-2 & 200 & 30 & 49.87 & 153.26 \\
MS-2-30-3 & 200 & 30 & 49.93 & 146.21 \\
MS-10-0-1 & 1000 & 0 & 49.87 & 42.96 \\
MS-10-0-2 & 1000 & 0 & 50.33 & 38.56 \\
MS-10-0-3 & 1000 & 0 & 48.02 & 45.36 \\
MS-10-15-1 & 1000 & 15 & 49.51 & 81.23 \\
MS-10-15-2 & 1000 & 15 & 50.97 & 86.58 \\
MS-10-15-3 & 1000 & 15 & 49.49 & 78.26 \\
MS-10-30-1 & 1000 & 30 & 50.87 & 107.21 \\
MS-10-30-2 & 1000 & 30 & 50.49 & 119.54 \\
MS-10-30-3 & 1000 & 30 & & 121.23 \\
\hline
\end{tabular}
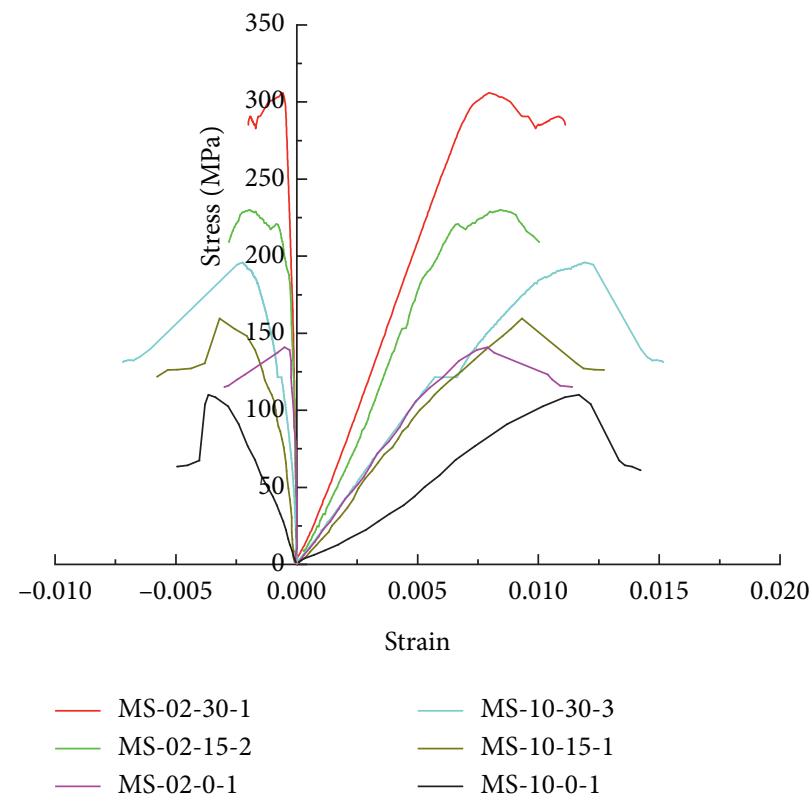

Figure 5: Stress-strain curves of mudstone specimens.

TABLE 2: Quantitative analysis of composition of mudstone based on fluorescence spectroscopy.

\begin{tabular}{lcc}
\hline Buried depth of mudstone & $200 \mathrm{~m}$ & $1000 \mathrm{~m}$ \\
\hline Ignition loss & 9.280 & 14.620 \\
$\mathrm{SiO}_{2}$ & 62.480 & 53.360 \\
$\mathrm{Al}_{2} \mathrm{O}_{3}$ & 16.450 & 24.560 \\
$\mathrm{TFe}$ & 5.240 & 3.870 \\
$\mathrm{FeO}$ & 4.460 & 2.680 \\
$\mathrm{~K}_{2} \mathrm{O}$ & 1.458 & 0.580 \\
Other & 0.632 & 0.330 \\
\hline
\end{tabular}




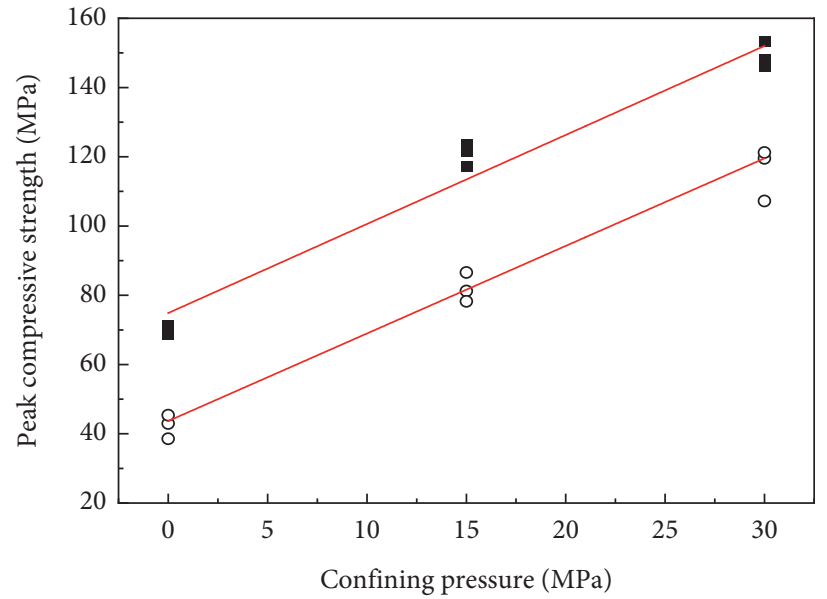

MS-02 series data points

MS-10 series data points

Figure 6: Peak strength versus confining pressure curve for the mudstone specimen.

TABLE 3: Relationship between peak strength and confining pressure.

\begin{tabular}{llr}
\hline Buried depth $(\mathrm{m})$ & Fitting equation & Correlation coefficient \\
\hline 200 & $y=2.571 x+74.875$ & 0.98406 \\
1000 & $y=2.529 x+43.682$ & 0.99708 \\
\hline
\end{tabular}

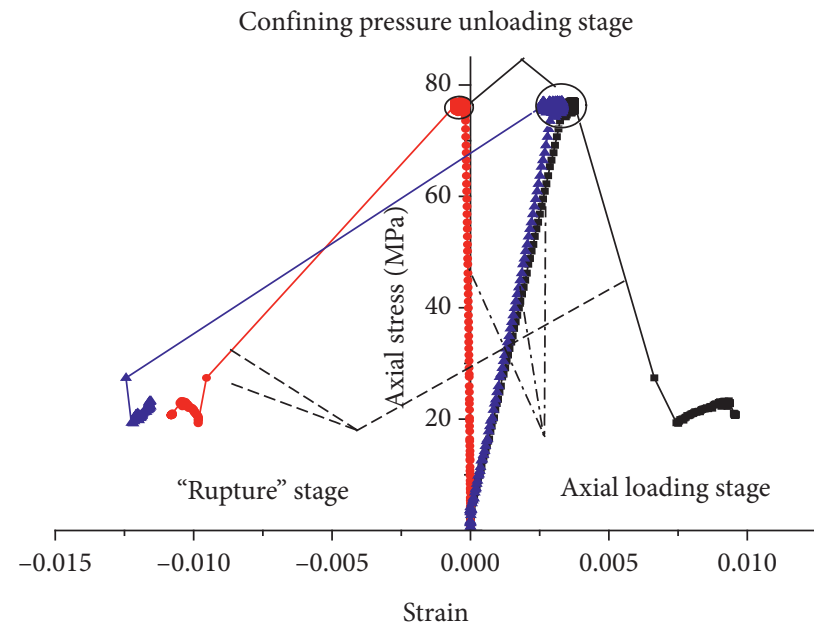

$\longrightarrow$ Longitudinal strain

$\rightarrow$ Circumferential strain

$\simeq$ Volumetric strain

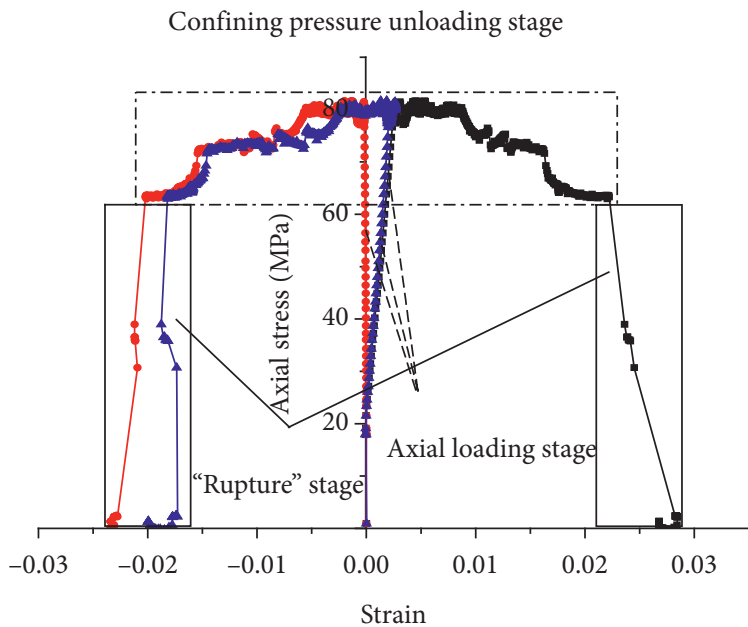

$\rightarrow$ Longitudinal strain

- Circumferential strain

$\rightarrow$ Volumetric strain

(a)

(b)

Figure 7: Axial stress versus strain curve for the mudstone specimens. (a) Depth $=200 \mathrm{~m}$. (b) Depth $=1000 \mathrm{~m}$.

triaxial pressure test of coal-rock seepage, the permeability of coal rock increases with the decrease in the confining pressure (within failure strength regime), but, during the early stage of confining pressure unloading in the seepage test, the permeability of both deep mudstone specimens decreases with the increase in confining pressure. With further unloading of confining pressure, unlike the mudstone with buried depth of $200 \mathrm{~m}$, the permeability of mudstone with buried depth of $1000 \mathrm{~m}$ gradually increases.

The permeability of mudstone is strongly correlated with its volume strain. According to Figure 10, after the axial compression stage, the specimen is subjected to different 


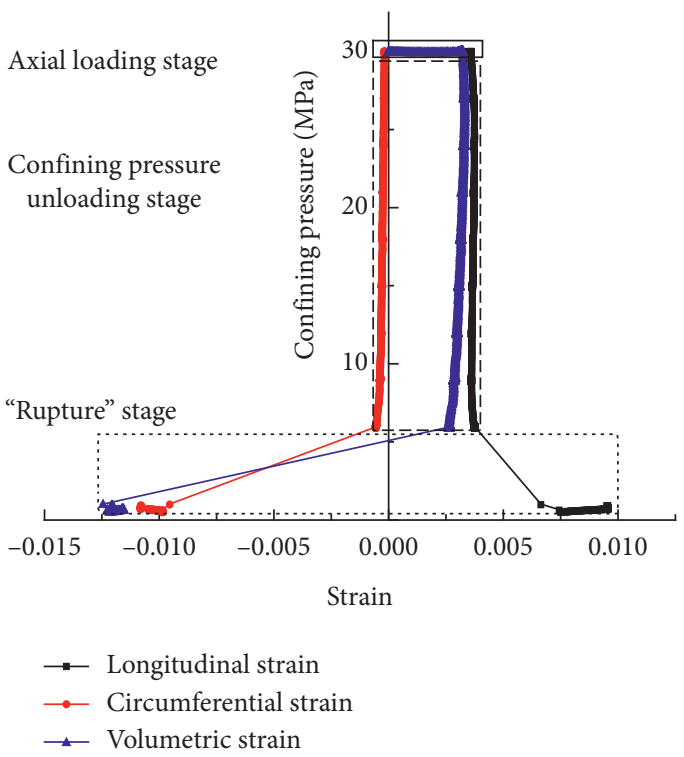

(a)

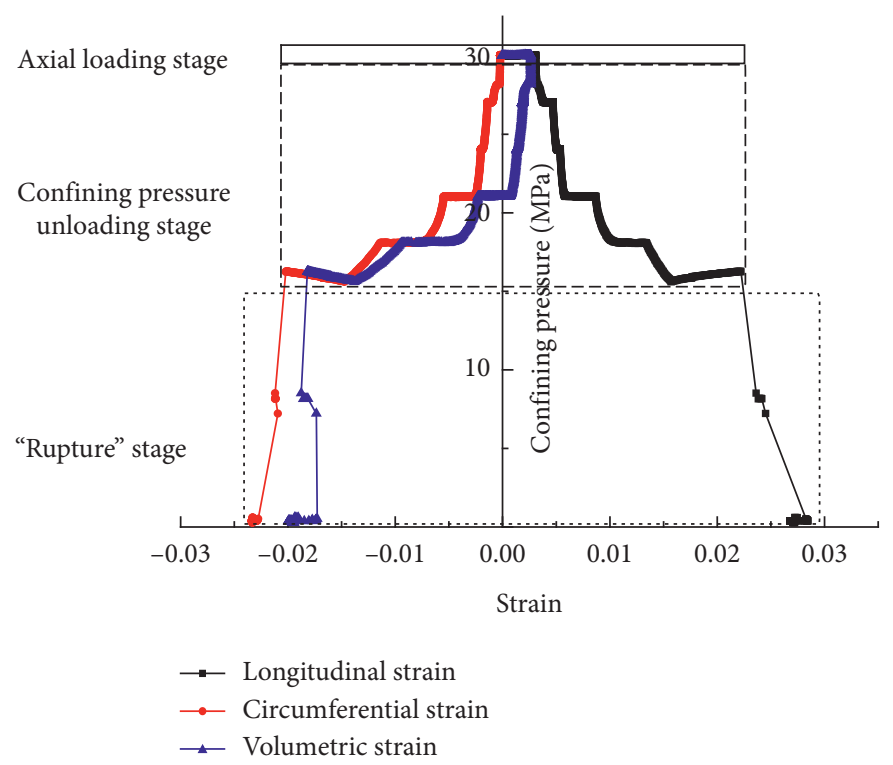

(b)

FIGURE 8: Confining pressure versus strain curve for the mudstone specimens. (a) Depth $=200 \mathrm{~m}$. (b) Depth $=1000 \mathrm{~m}$.

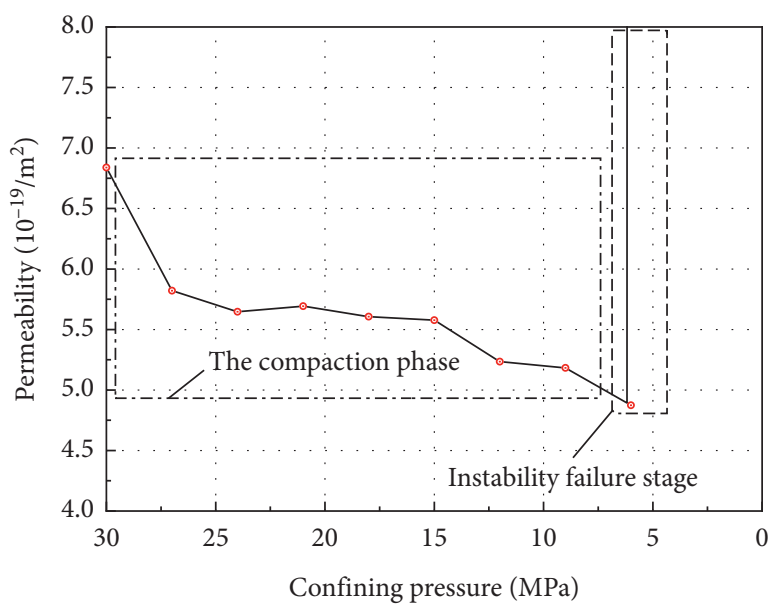

- - Buried depth: $200 \mathrm{~m}$ mudstone

(a)

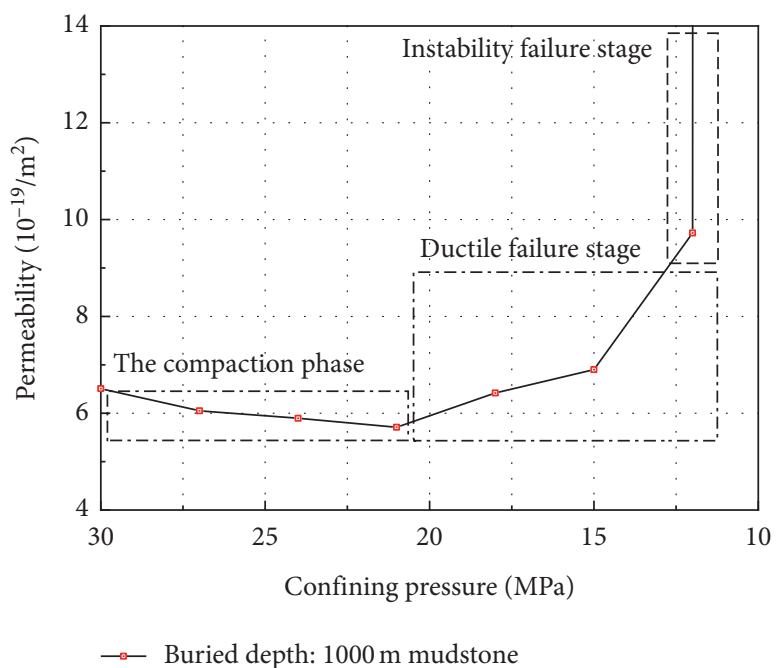

(b)

Figure 9: Mudstone permeability versus confining pressure. (a) Depth $=200 \mathrm{~m}$. (b) Depth $=1000 \mathrm{~m}$.

volume strains. During the initial stage of unloading, the deformation of two deep buried mudstones is close to the volume strain. Overall, the mudstone specimen begins to expand, and this process represents axial compression and circumferential expansion. According to the observed triaxial failure of mudstone, it is clear that the two sedimentary structures of deep buried mudstone resemble horizontal bedding. Before reaching peak intensity, with the unloading of the confining pressure, lower lateral bound of mudstone specimens is achieved. Because the axial stress remains basically constant, longitudinal compaction occurs, and the joint opening decreases gradually. The gas seepage is effectively related with the continuous blockage of channels. The fracture connection rate is reduced, and the gas permeability is also reduced. Due to the high compressive strength and low deformation of mudstone with buried depth of $200 \mathrm{~m}$, after unloading to $6 \mathrm{MPa}$, direct brittle failure is observed, and the mudstone transitions from expansion stage to instability failure stage. Further, the variation trend of permeability changes from decreasing to rapidly increasing. The mudstone with a depth of $1000 \mathrm{~m}$ shows different response. Figures 8 and 9 show that, after reaching the peak failure strength without rapid destruction, the mudstone exhibits deformation resistance. Consequently, the ductile failure stage of mudstone with buried depth of $1000 \mathrm{~m}$ occurs after the volume strain recovers to 0 . The deformation of mudstone continuously increases in the ductile failure stage. Further, the internal structure changes 


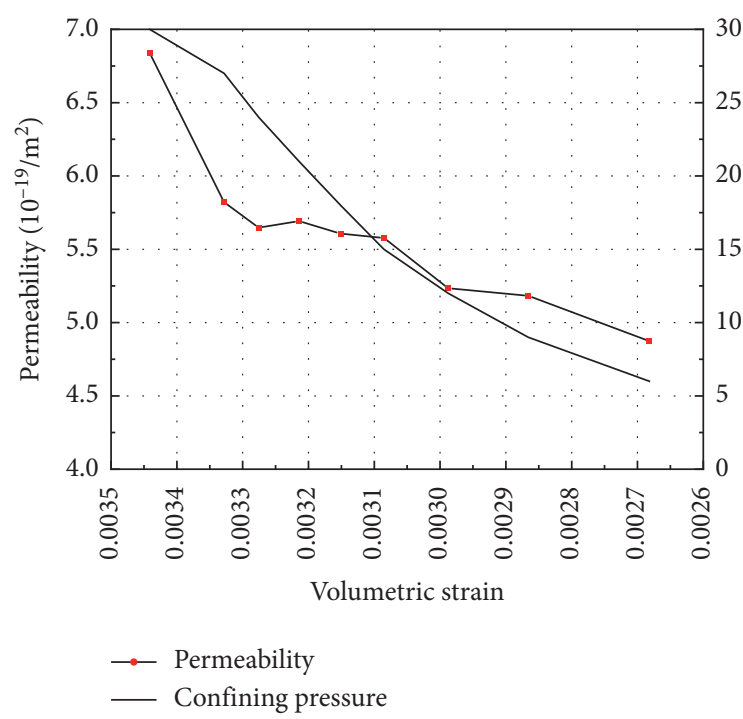

(a)

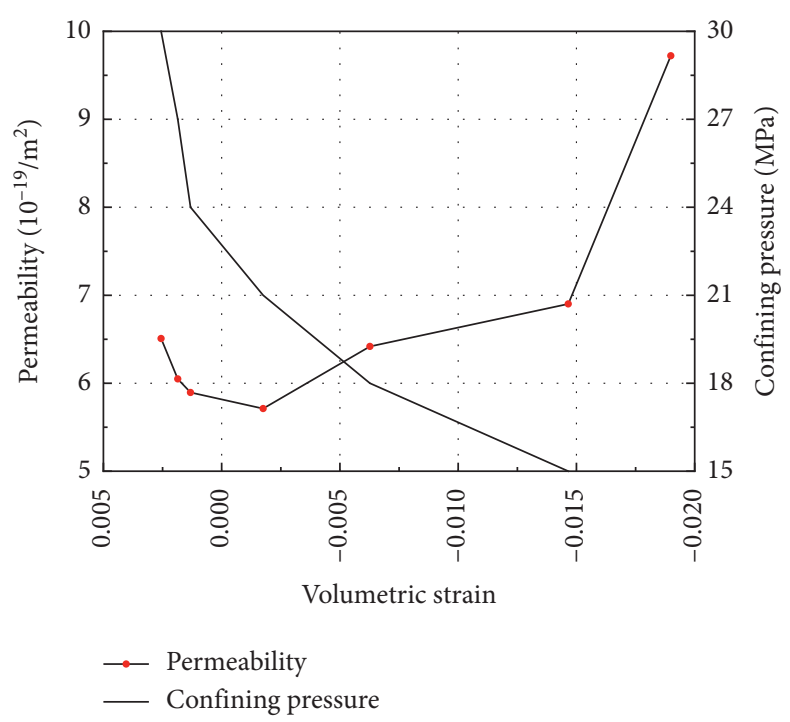

(b)

Figure 10: Volume strain versus permeability and pressure of mudstone. (a) Depth $=200 \mathrm{~m}$. (b) Depth $=1000 \mathrm{~m}$.

dramatically. The holes and cracks gradually collide, and the permeability increases. When the confining pressure is unloaded from $21 \mathrm{MPa}$ to $12 \mathrm{MPa}$, the permeability changes by $4 \times 10^{-19} \mathrm{~m}^{2}$, which is five times higher than the decrease in permeability during unloading from $30 \mathrm{MPa}$ to $21 \mathrm{MPa}$. As the confining pressure continues to unload, mudstone with buried depth of $1000 \mathrm{~m}$ becomes completely unstable, and the permeability increases rapidly.

\section{Conclusion}

To investigate the compressive strength and permeability characteristics of deep mudstone, conventional triaxial compression test and seepage test under confining pressure unloading were conducted on two kinds of deep buried mudstone from the 12th mining area of Pingmei, China. The main results of the study are summarized as follows:

(1) Unlike conventional hard rock, the triaxial compressive strength of mudstone with buried depth of $1000 \mathrm{~m}$ was much smaller than that of mudstone with buried depth of $200 \mathrm{~m}$. The peak strength of both specimens increased with the increase in confining pressure. For the mudstone specimen buried at a depth of $1000 \mathrm{~m}$, the effect of confining pressure on the peak strength was weak, but the effect of confining pressure on the deformation was strong.

(2) The confining pressure unloading test clearly discerned the axial pressure loading stage, confining pressure unloading stage, and fracture stage. The strain of mudstone buried at a depth of $200 \mathrm{~m}$ exhibited pointwise fluctuation with the increase in axial stress during the unloading of confining pressure. This mudstone exhibited fracture failure when the confining pressure was unloaded to $6 \mathrm{MPa}$, where it showed extremely strong brittle characteristics. The strain of mudstone buried at a depth of $1000 \mathrm{~m}$ fluctuated linearly with the increase in axial stress during confining pressure unloading. After the volume strain $(\Delta \varepsilon)$ reached 0.01 , it showed an oblique " $Z$ " fluctuation with the increase in axial stress. The mudstone exhibited fracture failure when the confining pressure was unloaded to $15 \mathrm{MPa}$, and the failure characteristics changed to brittle failure. The strain of mudstone buried at a depth of $1000 \mathrm{~m}$ decreased with the increase in confining pressure. The total strain at this stage was $74.44 \%$ of the volume strain variation in each stage of confining pressure unloading. Further, the confining pressure showed a power function relationship with the unloading pressure difference.

(3) The permeability of mudstone was found to be closely related to the volume strain. During the initial stage of confining pressure unloading, the volume strain of the two deep buried mudstones was close to 0 , and the permeability decreased gradually. With further unloading of confining pressure, the volume strain of mudstone increased gradually, and the permeability of the mudstone with buried depth of $1000 \mathrm{~m}$ was enhanced.

\section{Data Availability}

The data that support the findings of this study are available from the corresponding author upon reasonable request.

\section{Conflicts of Interest}

The authors declare that there are no conflicts of interest regarding the publication of this paper.

\section{Acknowledgments}

This work was supported by the National Key Research and Development Project of China (Grant no. 2016YFC0600704). 


\section{References}

[1] S. L. Crouch, "A note on post-failure stress-strain path dependence in norite," International Journal of Rock Mechanics and Mining Sciences \& Geomechanics Abstracts, vol. 9, no. 2, p. 197, 1972.

[2] D. W. Hobbs, "The strength and the stress-strain characteristics of coal in triaxial compression," The Journal of Geology, vol. 72, no. 2, p. 214, 1964.

[3] Y. S. Wu and Z. Y. Lin, "Experimental study on the mechanical properties of rock after failure under uniaxial compression," Chinese Journal of Geotechnical Engineering, vol. 1, p. 23, 1987.

[4] S. L. Qiu, X. T. Feng, C. Q. Zhang, H. Zhou, and F. Sun, "Experimental research on mechanical properties of deepburied marble under different unloading rates of confining pressures," Chinese Journal of Rock Mechanics and Engineering, vol. 29, p. 1807, 2010.

[5] Y. Liang, Q. Li, Y. Gu, and Q. Zou, "Mechanical and acoustic emission characteristics of rock: effect of loading and unloading confining pressure at the postpeak stage," Journal of Natural Gas Science and Engineering, vol. 44, p. 54, 2017.

[6] R. Huang and D. Huang, "Experimental research on mechanical properties of granites under unloading condition," Chinese Journal of Rock Mechanics and Engineering, vol. 27, p. 2205, 2008 .

[7] H. D. Chen, C. Yuan-Ping, H. X. Zhou, and W. Li, "Damage and permeability development in coal during unloading," Rock Mechanics and Rock Engineering, vol. 46, no. 6, p. 1377, 2013.

[8] P. Kang, L. Zhaopeng, Z. Quanle, Z. Zhenyu, and Z. Jiaqi, "Static and dynamic mechanical properties of granite from various burial depths," Rock Mechanics and Rock Engineering, vol. 52, no. 10, p. 3545, 2019.

[9] G. Y. Zhao, B. Dai, L. J. Dong, C. Yang, and J. Q. Zhou, "Energy conversion of rocks in process of unloading confining pressure under different unloading paths," Transactions of Nonferrous Metals Society of China, vol. 25, no. 5, p. 1626, 2015.

[10] Z. Q. Yin, X. B. Li, J. F. Jin, X. Q. He, and K. Du, "Failure characteristics of high stress rock induced by impact disturbance under confining pressure unloading," Transactions of Nonferrous Metals Society of China, vol. 22, no. 1, p. 175, 2012.

[11] M. Zhang, M. Lin, H. Zhu, D. Zhou, and L. Wang, "An experimental study of the damage characteristics of gascontaining coal under the conditions of different loading and unloading rates," Journal of Loss Prevention in the Process Industries, vol. 55, p. 338, 2018.

[12] Y. Xue, P. G. Ranjith, F. Gao et al., "Mechanical behaviour and permeability evolution of gas-containing coal from unloading confining pressure testsfining pressure tests," Journal of Natural Gas Science and Engineering, vol. 40, p. 336, 2017.

[13] W. G. Ren, H. W. Zhou, D. J. Xue, L. J. Wang, T. L. Rong, and J. F. Liu, "Mechanical behavior and permeability of coal and rock under strong mining disturbance in protected coal seam mining," Journal of China Coal Society, vol. 44, p. 1473, 2019.

[14] Z. Pan and L. D. Connell, "Modelling of anisotropic coal swelling and its impact on permeability behaviour for primary and enhanced coalbed methane recovery," International Journal of Coal Geology, vol. 85, no. 3-4, p. 257, 2011.

[15] K. Wang and F. Du, "Experimental investigation on mechanical behavior and permeability evolution in coal-rock combined body under unloading conditions," Arabian Journal of Geosciences, vol. 12, p. 1, 2019.

[16] H. Xie, X. Zhao, J. Liu, R. Zhang, and D. Xue, "Influence of different mining layouts on the mechanical properties of coalfluence of different mining layouts on the mechanical properties of coal," International Journal of Mining Science and Technology, vol. 22, no. 6, p. 749, 2012.

[17] Q. Zhang, X. Fan, Y. Liang et al., "Mechanical behavior and permeability evolution of reconstituted coal samples under various unloading confining pressures-implications for wellbore stability analysisfining pressures-implications for wellbore stability analysis," Energies, vol. 10, no. 3, p. 292, 2017.

[18] M. Verman, B. Singh, M. N. Viladkar, and J. L. Jethwa, "Effect of tunnel depth on modulus of deformation of rock mass," Rock Mechanics and Rock Engineering, vol. 30, no. 3, p. 121, 1997.

[19] Q. Y. Liu, R. Zhang, and M. Wang, "Physical properties of coal with different depths," Journal of China Coal Society, vol. 42, p. 2101, 2017.

[20] H. L. Wang, W. Y. Xu, J. Zuo, J. Shao, and C. Jia, "Evolution law of the permeability and porosity for low-permeability rock based on gas permeability test," Journal of Hydraulic Engineering, vol. 46, p. 208, 2015.

[21] E. Dana and F. Skoczylas, "Gas relative permeability and pore structure of sandstones," International Journal of Rock Mechanics and Mining Sciences, vol. 36, no. 5, p. 613, 1999.

[22] Z. P. Meng and S. P. Peng, "Mudstone composition of coal measures and its influence on the mechanical properties," Coal Geology and Exploration, vol. 2, p. 14, 2004. 